\title{
SUDORESE EM PACIENTES COM MOLÉSTIA DE CHAGAS CRôNICA
}

\author{
EDYMAR JARDIM*
}

Na moléstia de Chagas crônica há comprometimento do sistema nervoso central ou periférico, evidenciado pela considerável redução do número de neurônios em vários setores do organismo (animal e humano), nos quais tem-se aplicado o método de contagem neuronal. No cerebelo, no coração, no esôfago, na bexiga e na medula espinal essa redução do número de neurônios foi verificada de maneira categórica. No entanto, apesar dos relevantes fatos demonstrados pelos trabalhos anátomo-patológicos, diante dos quais não podem permanecer dúvidas de que a moléstia de Chagas é, realmente, uma afecção que atinge primàriamente o sistema nervoso, não é sempre fácil detectar as expressões clínicas das estruturas parcialmente denervadas. Resta-nos, para melhor compreensão da enfermidade, procurar estabelecer as relações clínico-patológicas dêstes achados, realizando estudos semiológicos apurados dos vários aparelhos e sistemas, a fím de que, conjugando estudos anátomo-patológicos e funcionais, possamos estabelecer os parâmetros da questão.

$\hat{E}$ nesse sentido que pretendemos, com o atual trabalho, verificar eventuais alteraçōes funcionais do sistema nervoso autônomo, estudando como se comporta a sudoração nos pacientes chagásicos crônicos.

\section{MATERIAL E MÉTODOS}

Foram estudados 10 pacientes registrados no Hospital das Clínicas da Faculdade de Medicina de Ribeirāo Prêto, com reação de Machado-Guerreiro positiva no sangue periférico, com títulos vários. Nāo levamos em consideração o tipo de alteração chagásica que os pacientes apresentavam, sendo que no grupo estudado havia casos de cardiopatias, de megacolo e de megaesôfago.

O grupo contrôle foí constituído de 10 pacientes com sindrome convulsiva. Em todos êles a reação de Machado-Guerreiro mostrou-se negativa (tabela 1).

Para a obtenção de sudoração empregamos estímulo calórico mediante colocaçăo dos pacientes no interior de um gabinete de madeira aquecido por lâmpadas de filamento de carvão, de modêlo por nós idealizado. Os pacientes permaneciam no interior do gabinete em decúbito dorsai, sendo permanentemente observados através de visores de vidro existentes nas paredes laterais da calxa. A temperatura foi controlada por um termômetro instalado internamente.

Para o estudo da distribuição topográfica da sudoração usamos o teste de amido-iôdo em tôda a superficie ventral dos pacientes.

* Professor Assistente do Departamento de Neurologia da Faculdade de Medicina de Ribeirāo Prêto (Prof. J. Armbrust-Figueiredo). 
A verificação ponderal foi feita mediante pesagens antes e depois das provas. Como dados correlatos da pesquisa anotamos as variações da pressão arterial, do pulso e da temperatura axilar.

O tempo médio de permanência no interior do gabinete aquecido foi de 20 minutos, suficiente para provocar sudoração difusa e profunda em todos os pacientes, com o deslocamento da temperatura entre os valôres de 23 e $42^{\circ} \mathrm{C}$ (tabela 2).

\begin{tabular}{|c|c|c|c|c|c|c|}
\hline Caso & $R . G$. & Nome & Sexo & Idade & Côr & Nacionalidade \\
\hline 1 & 14494 & M.S. & $F$ & 32 & B & Brasileira \\
\hline 2 & 20831 & P.M. & $M$ & 38 & B & Brasileira \\
\hline 3 & 18930 & A.L. & M & 53 & B & Brasileira \\
\hline 4 & 16543 & A.T. & $\mathbf{F}$ & 39 & B & Brasileira \\
\hline 5 & 20273 & F.P. & $\mathbf{M}$ & 36 & $\mathbf{P}$ & Brasileira \\
\hline 6 & 19768 & M.O. & M & 43 & $\mathbf{P}$ & Brasileira \\
\hline 7 & 46556 & L.T. & $\mathbf{F}$ & 39 & B & Brasileira \\
\hline 8 & 48132 & M.S. & $F$ & 34 & $\mathbf{P}$ & Brasileira \\
\hline 9 & 36861 & R.B. & $\mathbf{M}$ & 65 & $\mathbf{P}$ & Brasileira \\
\hline 10 & 34228 & A.M. & M & 46 & B & Brasileira \\
\hline 11 & 37371 & L.R. & $M$ & 38 & B & Brasileira \\
\hline 12 & 38254 & C.B. & F & 27 & B & Brasileira \\
\hline 13 & 34572 & M.M. & F & 32 & B & Brasileira \\
\hline 14 & 29194 & J.B. & $\mathbf{M}$ & 30 & B & Brasileira \\
\hline 15 & 11806 & W.G. & $\mathbf{M}$ & 20 & B & Brasileira \\
\hline 16 & 44895 & A.L. & $\mathbf{M}$ & 22 & B & Brasileira \\
\hline 17 & 44884 & S.F. & $F$ & 31 & B & Brasileira \\
\hline 18 & 31765 & A.O. & M & 18 & B & Brasileira \\
\hline 19 & 45749 & J.J. & $\mathbf{M}$ & 15 & B & Brasileira \\
\hline 20 & 39159 & A.F. & $\mathbf{F}$ & 24 & B & Brasileira \\
\hline
\end{tabular}

Tabela 1 - Dados de identificaçāo dos pacientes utilizados neste estudo. Na parte superior os relativos aos pacientes chagásicos com reação de Machado-Guerreiro positiva no sangue; na parte inferior o grupo contrôle de 10 pacientes epilépticos com reação de Machado-Guerreiro negativa. 


\begin{tabular}{|c|c|c|c|c|c|c|}
\hline \multirow[b]{2}{*}{ Caso } & \multicolumn{2}{|c|}{ Pêso corporal } & \multirow{2}{*}{$\begin{array}{c}\text { Diferenca } \\
\text { de pêso } \\
(\mathrm{g})\end{array}$} & \multirow{2}{*}{$\begin{array}{c}\text { Superficie } \\
\text { corporal } \\
\left(\mathrm{m}^{2}\right)\end{array}$} & \multirow{2}{*}{$\begin{array}{c}\text { Altura } \\
(\mathrm{cm})\end{array}$} & \multirow{2}{*}{$\begin{array}{c}\text { Perda } \\
\text { hidrica } \\
\left(\mathrm{g} / \mathrm{m}^{2}\right)\end{array}$} \\
\hline & $\begin{array}{l}\text { inicial } \\
(\mathrm{g})\end{array}$ & $\begin{array}{l}\text { final } \\
(\mathrm{g})\end{array}$ & & & & \\
\hline 1 & 44.400 & 44.300 & 100 & 1,35 & 148,5 & 74 \\
\hline 2 & 34.020 & 33.980 & 40 & 1,21 & 150,0 & 33 \\
\hline 3 & 56.900 & 56.620 & 280 & 1,56 & 160,0 & 79 \\
\hline 4 & 48.350 & 48.300 & 50 & 1,39 & 148,0 & 35 \\
\hline 5 & 49.100 & 48.950 & 150 & 1,52 & 165,0 & 98 \\
\hline 6 & 55.400 & 55.320 & 80 & 1,60 & 166,0 & 50 \\
\hline 7 & 55.850 & 55.800 & 50 & 1,58 & 163,0 & 31 \\
\hline 8 & 56.050 & $\mathbf{5 5 . 9 0 0}$ & 150 & 1,52 & 155,0 & 98 \\
\hline 9 & 45.800 & 45.700 & 100 & 1,47 & 166,0 & 68 \\
\hline 10 & 51.950 & 51.920 & 30 & 1,51 & 160,0 & 19 \\
\hline 11 & 70.800 & 70.300 & 500 & 1,80 & 167,5 & 277 \\
\hline 12 & 50.000 & 49.950 & 50 & 1,45 & 154,0 & 34 \\
\hline 13 & 60.200 & 60.100 & 100 & 1,55 & 151,0 & 64 \\
\hline 14 & 66.200 & 66.000 & 200 & 1,75 & 167,5 & 114 \\
\hline 15 & 65.400 & 65.200 & 200 & 1,74 & 170,0 & 114 \\
\hline 16 & 50.500 & 50.250 & 250 & 1,50 & 161,0 & 166 \\
\hline 17 & 60.700 & 60.500 & 200 & 1,69 & 170,0 & 118 \\
\hline 18 & 51.300 & 51.150 & 150 & 1,43 & 147,0 & 104 \\
\hline 19 & 47.000 & 46.850 & 150 & 1,48 & 164,0 & 101 \\
\hline 20 & 65.600 & 65.500 & 100 & 1,64 & 155,0 & 60 \\
\hline
\end{tabular}

Tabela 2 - Variações de pêso corporal e perda hídrica pela sudoração nos pacientes dos dois grupos estudados.

\section{RESULTADOS}

Do ponto de vista topográfico não veriffcamos diferenças fundamentais nos dois grupos estudados. Todos os pacientes apresentaram sudoração difusa em todos os segmentos corporais, havendo apenas variação da intensidade da côr escura que 
adquíre o amido-iôdo em presença do suor, em determinadas regióes. Através dêsse dado pudemos constatar que o processo sudoral se iniciou quase sempre pelo tronco, particularmente na região periumbelical e hipogástrica, alastrando-se ulteriormente para outras regiões. Menos vêzes o processo sudoral iniciou-se nos mem-

\begin{tabular}{|c|c|c|c|c|c|c|c|c|}
\hline \multirow{3}{*}{ Caso } & \multicolumn{4}{|c|}{ Pressão arterial } & \multicolumn{2}{|c|}{ Pulso } & \multicolumn{2}{|c|}{ Temperatura } \\
\hline & \multicolumn{2}{|c|}{ inicial } & \multicolumn{2}{|c|}{ final } & \multirow{2}{*}{ inicial } & \multirow{2}{*}{ final } & \multirow{2}{*}{ inicial } & \multirow{2}{*}{ final } \\
\hline & $(\mathrm{mx})$ & $(\mathrm{mn})$ & $(\mathrm{mx})$ & $(\mathrm{mn})$ & & & & \\
\hline 1 & 12 & 8 & 11 & 8 & 84 & 100 & 36,5 & 37,5 \\
\hline 2 & 10 & 6 & 9 & 6 & 92 & 108 & 36,4 & 38,1 \\
\hline 3 & 14 & 9 & 12 & 7 & 104 & 108 & 37,8 & $\mathbf{3 7 , 4}$ \\
\hline 4 & 10 & 7 & 12 & 7 & 42 & 48 & 36,7 & 37,6 \\
\hline 5 & 11 & 6 & 10 & 6 & 42 & 57 & 36,4 & 37,4 \\
\hline 6 & 12 & 8 & 12 & 8 & 64 & 70 & 36,0 & 37,3 \\
\hline 7 & 12 & 7 & 11 & 6 & 74 & 96 & 36,9 & 38,2 \\
\hline 8 & 17 & 7 & 15 & 7 & 66 & 66 & 35,8 & 37,3 \\
\hline 9 & 14 & 9 & 13 & 8 & 110 & 118 & 36,2 & 37,6 \\
\hline 10 & 9 & 6 & 9 & 6 & 86 & 88 & 35,6 & 36,8 \\
\hline 11 & 12 & 8 & 12 & 8 & 68 & 72 & 36,5 & 37,6 \\
\hline 12 & 12 & 8 & 12 & 7 & 88 & 106 & 36,7 & 37,8 \\
\hline 13 & 14 & 8 & 12 & 7 & 92 & 92 & 37,2 & 37,8 \\
\hline 14 & 12 & 8 & 12 & 8 & 72 & 82 & 36,1 & 37,9 \\
\hline 15 & 15 & 9 & 14 & 8 & 84 & 88 & 36,6 & 37,5 \\
\hline 16 & 12 & 8 & 11 & 7 & 74 & 92 & 36,0 & 37,8 \\
\hline 17 & 12 & 8 & 11 & 7 & 78 & 82 & 37,0 & 37,9 \\
\hline 18 & 12 & 8 & 11 & 7 & 61 & 82 & 35,8 & 37,7 \\
\hline 19 & 11 & 7 & 12 & 6 & 76 & 110 & 36,6 & 37,7 \\
\hline 20 & 11 & 7 & 11 & 7 & 82 & 112 & 36,3 & 37,8 \\
\hline
\end{tabular}

Tabela 3 - Variações da pressão arterial, do pulso e da temperatura nos dois grupos de pacientes estudados. 
bros inferiores ou superiores. Pràticamente em todos os casos houve nitido predomínio de sudoração do tronco, avaliado pela intensidade de coloração. O membro superior direito em muitos pacientes apresentou maior intensidade de coloração que o esquerdo.

Não verificamos áreas com ausẽncia de sudoração em qualquer dos casos estudados.

O estudo ponderal foi realizado pesando-se os pacientes no início e no fim dos testes, calculando-se a diferença entre as pesadas (tabela 2). Esta diferença fol dividida pela superficie corporal, dando-nos como resultado a perda hidrica em $\mathrm{g} / \mathrm{m}^{2}$ de superfície corporal. O grupo chagásico perdeu em média $68,5 \mathrm{~g} / \mathrm{m}^{2}$ e o grupo controle $115,2 \mathrm{~g} / \mathrm{m}^{2}$.

A verificação da pressāo arterial não mostrou diferenças significativas, sendo as variações pràticamente idênticas para ambos os grupos, como pode ser visto na tabela 3 .

O pulso mostrou uma variação (média) de 9,5 batimentos por minuto para 0 grupo chagásico e de 14,3 batimentos por minuto para o grupo contrôle, em relacăo ao seu valor Inicial.

O aumento médio da temperatura axllar foi de $1,19^{\circ} \mathrm{C}$ para o grupo chagásico e de $1,27^{\circ} \mathrm{C}$ para normal.

No decorrer das provas, alguns pacientes queixaram-se de tonturas e mal-estar geral. Não houve referências a outras alterações.

\section{COMENTARIOS}

A análise dos resultados leva-nos à conclusão de que os pacientes com moléstia de Chagas crônica, submetidos à mesma temperatura ambiente durante um tempo determinado, apresentam perda hidrica significativamente menor que aquela dos indivíduos não chagásicos. Os valôres correspondentes a essas perdas constam da tabela 2 e deixam em evidência a diferença de quantidade de sudoração, para menos nos chagásicos, em relação aos não chagásicos, pois percentualmente sua média de sudorese corresponde a apenas $59,4 \%$ dos valôres do grupo contrôle. Diante dêste resultado devemos então dar nossa interpretação.

Schwartzburd e Köberle ${ }^{4}$, em estudos experimentais em ratos, demonstraram extensas lesões medulares, particularmente na substância cinzenta, representadas por grande redução do número de neurônios. Vichi ${ }^{7}$, confirmando os achados de Schwartzburd e Köberle, demonstrou o intenso parasitismo da medula espinal de ratos, mediante estudo quantitativo de pseudocistos leishmanióticos. Brandão ${ }^{1}$, em estudo quantitativo de neurônios em gânglios simpáticos e parassimpáticos de ratos, não encontrou redução estatìsticamente significante nos gânglios simpáticos. Tafuri e Raso ${ }^{5}$, estudando os gânglios simpáticos de camundongos albinos infectados experimentalmente pelo $T$. cruzi, encontraram lesões nestes gânglios, porém de maneira muito irregular e imprevista.

Vieira ${ }^{6}$ verificou hipersudação em pacientes chagásicos crônicos, utilizando como excitante a pilocarpina injetada subcutâneamente. A hipersudação encontrada pelo referido autor, coloca em evidência a integridade do sistema efetor (ou pós-ganglionar) e que é explicada pela lei de Cannon, 
ou seja, da hipersensibilidade das estruturas denervadas aos estímulos quimicos.

Diante de nossos resultados e baseados nos trabalhos experimentais a que nos referimos, parece-nos razoável atribuir a nítida redução de sudoração que encontramos no grupo chagásico, a um processo de denervação parcial em nivel pré-ganglionar medular.

$\hat{E}$ verdade que alterações neuronais ao nivel do hipotálamo poderiam, pelo menos teỏricamente, explicar os resultados encontrados. A destruição neuronal não fica, na moléstia de Chagas, adstrita apenas ao nível medular, mas compromete estruturas superiores, como demonstramos em $1962^{2}$, evidenciando considerável destruição das células de Purkinje em camundongos infectados experimentalmente pelo $T$. cruzi. No entanto, estudos patológi$\cos$ quantitativos em niveis diencefálicos não foram ainda realizados.

Com relação à diferença na média de freqüência cardíaca entre o grupo chagásico e o contrôle, que fòi respectivamente de 9,5 e 14,3 batimentos por minuto, parece-nos que o achado possa ser explicado por uma menor capacidade de resposta do coração chagásico a estímulos vários. Tal hipótese encontra apoio no quadro do bloqueio sinoatrial autonômico, descrito por Brasil 2.

\section{RESUMO}

Foi estudada a sudoração em pacientes com moléstia de Chagas crônica, mediante estímulo térmico (teste de Minor). As perdas hídricas dos pacientes chagásicos foram significativamente menores do que as dos pacientes não chagásicos.

\section{SUMMARY}

Sweating in patients with chronic Chagas' disease

The sweating in patients with chronic Chagas' disease by using thermic stimulus (Minor test) is studied. The loss of water was significantly lower in the patients with Chagas' disease when compared with the loss in non chagasic patients.

\section{REFERENCIAS}

1. BRANDAO, H. J. S. - Estudo quantitativo de neurônios simpáticos e parassimpáticos na moléstia de Chagas experimental em ratos. Tese de doutoramento, Faculdade de Medicina de Ribeirão Prêto, 1961.

2. BRASIL, A. - Autonomical sino-strial block: a new disturbances of the heart mechanism. Arq. Bras. Cardiol. 8:159-212, 1955.

3. JARDIM, E. - Alteraçōes quantitativas das células de Purkinje na fase aguda da moléstia de Chagas experimental no camundongo. Tese de doutoramcnto, Faruldade de Medicina de Ribeirão Prêto. 1962. 
4. SCHARTZBURD, H. \& KOBERLE, F. - Chagas Myelopathie. Zeitschr. f. Tropenmed. u. Parasit. 10:309-314, 1959.

5. TAFURI, W. L. \& RASO, P. - Lesōes do sistema nervoso autônomo do camundongo albino na tripanosomiase. Hospital (Rio de Janeiro) 62:1325-1342, 1962.

6. VIEIRA, C. B. - Hipersudação provocada pela pilocarpina na moléstia de Chagas crônica. Hospital (Rio de Janeiro) 64:1335-1345, 1963.

7. VICHI, F. L. - Estudo do parasitismo na medula espinal de ratos na fase aguda da moléstia de Chagas. Rev. Inst. Med. Trop. São Paulo 3:37-42, 1961.

Departamento de Neurologia - Faculdade de Medicina - Ribeirão Prêto, SP - Brasil. 